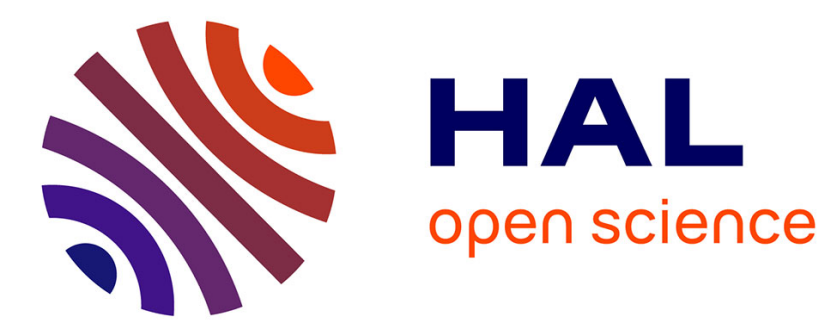

\title{
Field studies need to report essential information on social organisation - independent of the study focus
}

Lindelani Makuya, Charlotte-anaïs Olivier, Carsten Schradin

\section{To cite this version:}

Lindelani Makuya, Charlotte-anaïs Olivier, Carsten Schradin. Field studies need to report essential information on social organisation - independent of the study focus. Ethology, 2021, 10.1111/eth.13249 . hal-03457477

\section{HAL Id: hal-03457477 \\ https://hal.science/hal-03457477}

Submitted on 30 Nov 2021

HAL is a multi-disciplinary open access archive for the deposit and dissemination of scientific research documents, whether they are published or not. The documents may come from teaching and research institutions in France or abroad, or from public or private research centers.
L'archive ouverte pluridisciplinaire $\mathbf{H A L}$, est destinée au dépôt et à la diffusion de documents scientifiques de niveau recherche, publiés ou non, émanant des établissements d'enseignement et de recherche français ou étrangers, des laboratoires publics ou privés. 


\section{Field studies need to report essential information on}

\section{2 social organization - independent of the study focus}

3

4 Makuya, L. ${ }^{1}$, Olivier, C.A. ${ }^{1,2}$ \& Schradin, C. ${ }^{1,2}$

5

6

7

8

9

10 WITS 2050, Johannesburg, South Africa

7 Abstract
Published as

Makuya, L., Olivier, C.-A. \& Schradin, C. 2022. Field studies need to report essential

${ }^{1}$ School of Animal, Plant \& Environmental Sciences, University of the Witwatersrand, Private Bag 3,

${ }^{2}$ IPHC, UNISTRA, CNRS, 23 rue du Loess, 67200 Strasbourg, France

Comparative studies on social evolution are ideally based on large datasets to ensure high statistical power, but their scientific validity also relies on the quality of the data. However, even though social organization, i.e., the composition of social units, is measured in many field studies testing specific hypotheses, these data are often not adequately reported. Here, 
22 we summarise which data on social organization should always be reported regardless of the

23 study focus to make them available for comparative studies. As an example, we report data

24 from a literature survey on one of the four superorders of placental mammals, the Xenarthra

25 from South America (armadillos, anteaters and sloths), of which all 30 species are generally

26 assumed to be solitary living. In total we found 4510 articles. The titles and abstracts of 61

27 publications indicated that data on social organization were collected, but only 12

28 publications contained sufficient information for us to determine the social organization. We

29 found reliable information on nine species, of which seven were strictly solitary. Two species

30 showed a combination of solitary-living and pair-living with one including female groups. This

31 review therefore indicates that Xenarthra may not be exclusively solitary. Our literature

32 survey further shows that valuable data are often not reported even though it can be assumed

33 that these data had been collected. We report examples from 23 additional studies on

34 monotremes, marsupials, and two other placental superorders showing similar issues in

35 reporting data. It is important to make authors aware that this information would be valuable

36 for comparative studies. In sum, we recommend including data on the composition of social

37 units, sex of individuals, occupancy of sleeping sites, frequency of observations and trapping

38 events, home range overlap, and the proportion of the individuals in the study area,

39 independent of the study question in all publications.

41 Keywords: Comparative study; Field data; Intraspecific variation; Social organization; Social

42 system; Social structure 
46 Comparative studies yield significant insight into the evolution of social systems (Chak et al.,

47 2017; Cornwallis et al., 2017; Firman et al., 2020; Griesser et al., 2017; Lukas \& Clutton-Brock,

48 2013). The quality of such comparisons has increased over the last decades due to significant

49 improvements in statistical methods that correct for phylogeny and enable us to include

50 ecological and life-history factors (Garamszegi, 2014). However, the quality of comparative

51 studies also depends on the quality of the used database (Schradin, 2017). Many researchers

52 focused on getting a large, instead of an accurate, database, for example by using

53 phylogenetic inferences to add species that had not been studied (birds: Cockburn, 2006;

54 used also by Gonzalez et al., 2013; Jetz \& Rubenstein, 2011; mammals: Lukas \& Clutton-Brock,

55 2013). There are now statistically sound methods to infer missing phylogenetic data points

56 (for example see Callaghan et al. (2021)), which are useful when the important life-history

57 and ecological data for a few species are known, so that one can include these species.

58 However, such inference should only be done if the social data are missing from just a few

59 but not the majority of species (Schradin, 2017). Furthermore, information assuming the

60 social system from anecdotal observations or expert opinion published in secondary and

61 tertiary sources has often been included for species that have never been studied in the field

62 (Schradin, 2017). This has been criticised and a more careful approach has been

63 recommended (Griesser \& Suzuki, 2016; Huck et al., 2020), i.e. to only use data from studies

64 where animals have been studied in their natural environment (Schradin, 2017). However,

65 while the number of field studies has increased over the last decades (Schradin \& Hayes,

66 2017), basic data on social systems are often not reported in a way that makes them useable

67 for comparative studies. 

research and not on describing the social system of species (Clutton-Brock \& Janson, 2012).

70 Social organization, which means the sex and the composition of social units, is one of the 71 four key components of social systems (Kappeler \& van Schaik, 2002). Social organization is easier to observe and to record than the three other components of the social system 73 (Schradin et al., 2018), which are the mating system (who reproduces with whom), the social structure (social interactions; social networks) and the parental care system (who takes care of the offspring) (Kappeler, 2019). While field researchers often record the composition of study groups, details of such basic data are often not reported in the arising publications that test specific hypotheses.

The conclusions from hypothesis-driven research are important to test and develop theory; however; conclusions can change and the main values of each study are the data that were recorded. It is as important to include these data and the conclusions drawn from them. The availability of published data has been recognised as being of crucial importance analyses data are more valuable than interpretations. This is demonstrated by the example of intra-specific variation in social systems (Lott, 1984; Schradin et al., 2018). For example, if a study population is reported to be pair-living because most animals live in pairs but some populations or individuals also live solitarily or in groups, then biologically meaningful variation might be missed. We have been building a database on mammalian social evolution since 2015 (Agnani et al., 2018; Valomy et al., 2015). For this, we have searched more than ten thousand peer-reviewed articles for information about the composition of social units, focusing on data reported in the methods and results sections. We noticed that many field

91 studies that presumably collected such data did not report them, but instead assigned a 
general form of social organization to the study population in the introduction and / or discussion.

The aim of the current paper was to identify which data are often missing from publications even though they probably had been collected and could have been used to accurately assign social organization, including its variation. For this, we surveyed the literature on one mammalian superorder as an example, the Xenarthra (armadillos, sloths and ant-eaters), and added more examples from other mammalian taxa. We chose this superorder as it is small, containing only 30 species, all of which had been assumed to live solitary (Lukas \& Clutton-Brock, 2013). Our aims were to (1) provide an overview of what is known regarding the social organization of Xenarthra, (2) identify which information is missing in published field studies on Xenarthra to correctly characterise their social organization, (3) report additional examples from other mammalian taxa, and finally (4) provide a template for field researchers on which data to provide in every published paper so that they are available for comparative studies of social evolution.

\section{Methods}

Xenarthra social organization

The Xenarthra (armadillos, sloths and anteaters) is one of four superorders within the placentals; with the other three being Afrotheria (elephants, sea cows and elephant-shrews), Euarchontaglires (primates and rodents) and Laurasiatheria (bats, carnivores and ungulates) (Wildman et al., 2007). Xenarthra mainly occur in South America, with one species ranging to 
114 North America. They consist of 30 species of which 20 belong to the order Cingulata

115 (armadillos) and 10 to the order Pilosa (six species of sloths and four species of anteaters).

116 Xenarthra are typically considered to be solitary living (Lukas \& Clutton-Brock (2013)

117 categorised all 24 Xenarthrans in their database as solitary living), though it has been

118 acknowledged that small groups might occur (Nowak \& Wilson, 1999; Wilson \& Mittermeier, 119 2018). Determining the social organization of species in this superorder is important for 120 comparative studies regarding mammalian social evolution.

Data collection and literature review Xenarthra

123 Literature research was done from the $27^{\text {th }}$ July 2020 until the $30^{\text {th }}$ June 2021 . During this

124 period a species list of the extant members of the superorder Xenarthra was compiled using 125 the IUCN Red List of Threatened Species (www.iucnredlist.org). Using this list, a search was 126 conducted on the primary literature on social organization in Web of Science and Google 127 Scholar. The search string used to assemble this information consisted initially of the term social in conjunction with the species scientific name or common name. For example, the 129 search string used for the Northern long-nosed armadillo Dasypus sabanicola was ("Dasypus sabanicola" OR "Northern long-nosed armadillo" AND "social"). If no records were found with

131 the initial search string, then a second search string was used that consisted only of the 132 scientific species name (e.g., "Dasypus sabanicola"). If the second search string still yielded no results, then the final search string used was just the genus name and the term social (e.g., "Dasypus" AND social). Within the search results from Web of Science, the following research areas were selected to refine the results - "zoology", "behavioural science" and 
that were not applicable to the topic were removed from the generated database. From the remaining articles the abstracts were read and reviews not reporting primary data or studies done on captive animals were excluded from the database. The PDFs of the remaining publications were then obtained and searched for the following terms related to social organization: "social," "group," "territorial," "solitary," "bachelor," "plural," "aggregation," gregarious", "pair" and "singular." The figures, tables and supplementary materials were also checked for information that may not have been recorded in the main text. The same process was applied in Google scholar to search for additional articles.

The social organization described in the primary literature for each of the species was recorded according to the following categories (for details see (Agnani et al., 2018; Valomy et al., 2015): "solitary," "pair," "one male multiple females," "one female multiple males," "multiple males and multiple females."

\section{Data from other mammalian taxa}

We are in the process of building a database on mammalian social organization reported from field studies using the same methods as described above. In addition to the detailed case study on Xenarthra, we also reported examples from several other mammalian taxa, but without the claim to cover all species in these taxa.

\section{Data analysis}

The following variables were calculated from the information provided from the literature. The total number of social units observed per population and per species was summed up. 
Then the main social organization was determined by the most commonly observed social organization. Following this, the percentage of main social organization was calculated by dividing the number of social units of the main social organization by the total number of social units multiplied by 100 . Finally, intra-specific variation in social organization (IVSO) was determined as within population when variation occurred only within a population, among populations when variation occurred among populations only, both if variation occurred within and among populations, and none if there was no variation reported.

\section{Results}

\section{Xenarthra}

We found 4510 articles (1801 for Pilosa and 2709 for Cingulata). The titles from 61 articles (30 for Pilosa and 31 for Cingulata) indicated that information on social organization was collected. These articles were searched in detail for information. Twelve publications provided information on social organization for 15 populations of nine of the 30 Xenarthran species. From these nine species, the following seven species were reported to be exclusively solitary: southern naked-tailed armadillo, Cabassous unicinctus (Desbiez et al., 2018), giant armadillo, Priodontes maximus (Desbiez et al., 2019), nine-banded armadillo, Dasypus novemcinctus, (McDonough, 2000), maned three-toed sloth, Bradypus torquatus (Falconi et al., 2015), Hoffmann's two-toed sloth, Choloepus hoffmanni (Vaughan et al., 2007), southern tamandua, Tamandua tetradactyla (Rodrigues et al., 2001) and giant anteater, Myrmecophaga tridactyla (Di Blanco et al., 2017; Medri \& Mourão, 2005; Shaw et al., 1987). Two Pilosa species showed intra-specific variation in social organization. In the pale-throated three-toed sloth, Bradypus tridactylus (Taube et al., 1999), solitary living (of both sexes), pair- 
living, and multi-female groups were reported. In the brown-throated sloth, Bradypus variegatus, solitary living (of both sexes) and pair-living was reported (Garcés-Restrepo et al., 2017; Pauli \& Perry, 2012).

While the title and abstract of 61 publications indicated that data on social organization was collected, only 12 publications contained useable information. Most of the 49 remaining studies focussed on population dynamics $(N=14)$, habitat use $(N=12)$, or other ecological aspects such as conservation, spatial ecology, or monitoring via camera traps (see ESM 1). Most studies could not be used to correctly determine social organization because they either did not report the sex of individuals or state the composition of the social units they observed (for example they observed / trapped / tracked individuals but did not present data whether they were solitary or not; Table 1). Studies using radio-tracking often failed to report whether or not individuals shared home ranges and sleeping sites (Table 1). One study had information we could use for our database for one species (Bradypus tridactylus) and missing information for the other species (Choloepus didactylus) (Taube et al., 1999).

\section{Other mammalian taxa}

Examples from other mammalian taxa show that the same information to determine social organization is often missing, just as for Xenarthra (Table 1; ESM 2). For example, in Perissodactyla, groups have been observed in onagers (Equus hemionus) and kiangs (E. kiang) without the sex of the individuals being reported (ESM2), which would be essential to determine the sex composition of the social units, i.e., whether it is one male with several females, multi-male multi-female groups, or all male and all female groups. The same problem occurred in several species of kangaroos (ESM2). In platypus (Ornithorhynchus 
anatinus), which are typically regarded to be solitary living (Wilson \& Mittermeier, 2015), den sharing has been reported repeatedly, but not whether the same individuals permanently share one den and home range, or whether such associations were short lived, representing random aggregations at preferred resting sites (ESM 2).

\section{Discussion}

It is mandatory to have access to reliable field data of animal social systems if one wants to do comparative studies on social evolution (Schradin, 2017). Conducting field studies is costly in time and funding (Clutton-Brock \& Sheldon, 2010; Schradin \& Hayes, 2017). It is, therefore, both surprising and frustrating when such valuable data are collected but not reported. Here we report in detail for one superorder of placentals, the Xenarthra, that most conducted field studies do not report data essential to accurately determine social organization. We further add examples from other mammalian taxa indicating similar problems. Data on social organization are valuable and difficult to collect; therefore, we give advice on how to report such data in the future, independent of the study focus.

So far, Xenarthrans, which represents sloths, anteaters and armadillos, have been believed to live solitarily (Wilson \& Mittermeier, 2018). This might be the reason why most field studies on Xenarthrans did not report the composition of social units: possibly the authors were assuming that it is clear that they are solitary. However, in our literature survey we found some indication that some species of Xenarthrans show intra-specific variation in social organization, including pair-living and female groups. The Xenarthra represent one of four mammalian superorders, such that the social organization of these species might have a 
significant impact on comparative studies regarding mammalian social evolution. From our point of view, while solitary living is the most common form of social organization in 230 Xenarthra, ignoring other possible forms of social organization in this taxon could lead to mistakes in comparative studies of mammals. To prevent such mistakes from occurring, field data from long-term monitoring of natural populations is essential; however, this data is often 233 missing.

In another database, all Xenarthra were classified as solitary living (Lukas \& Clutton-

Brock, 2013). It is important to note that there is agreement that comparative studies need clear definitions (Lukas \& Clutton-Brock, 2017; Schradin, 2017). For example, Lukas \& CluttonBrock (2013) had a more stringent definition to classify species as pair-living than we had: pairs had to be together for more than one breeding season (Lukas \& Clutton-Brock, 2013). Whereas we recorded pairs in pale-throated three-toed sloths (Bradypus tridactylus; Taube et al. (1999)) even though it was unknown for which time they stayed together. In contrast, using radio-tracking in brown-throated sloths (Bradypus variegatus), the authors indicate mate fidelity of one female remaining in the home range of one male for 3 years (Fig 3a in Garcés-Restrepo et al. (2017)), and the female mated only with this male, such that it can be regarded as a pair (Garcés-Restrepo et al., 2017). We did not consider observed pairs in ninebanded armadillos (Dasypus novemcinctus) as indication for pair-living, because pairs were only present during courtship and mating, indicating a solitary form of social organization 247 (McDonough, 2000). The secondary literature also reports some degree of sociality for some Xenarthra, for example female groups in Hoffmann's two-toed sloth (Choloepus hoffmanni; 249 Nowak \& Wilson (1999)), groups in pale-throated three-toed sloths (Bradypus tridactylus, Wilson \& Mittermeier (2018)), and groups of adult offspring staying together in nine-banded 251 armadillos (Dasypus novemcinctus, Nowak \& Wilson (1999)). In sum, some data from the 
primary literature (Garcés-Restrepo et al., 2017; McDonough, 2000; Taube et al., 1999) and reports from secondary literature (Nowak \& Wilson, 1999; Wilson \& Mittermeier, 2018)

254 indicate that Xenarthra might be less asocial than generally assumed. Whether to score these species as solitary, variable in their social organization, or excluding them due to uncertainties from further comparative analysis will have to depend on the specific study objective.

A similar problem as in Xenarthra exists for monotremes, which are all generally believed to be solitary living (Wilson \& Mittermeier, 2015). However, numerous reports of den sharing in the platypus (Ornithorhynchus anatinus), covering decades of studies (Grant et al. 1992; Serena 1994; Serena et al. 1998 and older reports cited within), indicate that this general assumption might not cover the full range of social organization occurring in this species.

While in Xenarthra and monotremes, the general assumption that they live solitarily might explain why researchers are reluctant to report data on social organization. Alternatively, in group-living species we found that the correct group composition could often not be determined as no information about the sexes was given such as in Perissodactyla, Carnivora, Rodentia, and Marsupialia. However, whether the social organization consists of one male with multiple females or multiple males and multiple females, has a significant influences on other aspects of the social system, for example the mating system and the social 270 structure (Kappeler, 2019). In sum, we found throughout the mammalian taxa, examples of 271 field studies that likely collected data on social organization without reporting it. This can lead 272 to the misclassification and ignorance of important variation (Schradin et al., 2018), therefore 273 affecting the outcome of comparative studies (Schradin, 2017). 
274 To compensate for missing data, others solved this by using phylogenetic

275 interferences (assuming closely related species have the same social system), included data

276 from captive studies, and expert opinions, with the risk of coming to wrong conclusions

277 (Schradin et al., 2018). Here we argue for field researchers to report life-history data in a

278 precise way, making it possible to accurately determine the social organization and especially

279 the composition of social units, one of the key components of social systems (Kappeler, 2019).

280 Sometimes it is impossible for researchers to give the correct information about the sex

281 composition of social units, especially in species forming large herds (Moehlman 1998;

282 Rudman 1998) or when individuals are not captured, sexed, and individually marked.

283 However, when such information is routinely collected, it should also be reported. In

284 Xenarthra, this problem exists for studies published during the last 4 decades and was even

285 dominant during the last decade (ESM1); indicating that it is not a problem of research 286 methodology, but of publishing culture. We argue that in future, it is important to report such

287 data even if the study focus is on a different topic.

Kappeler (2019) defined the social organization as the composition of social units,

which was inferred by previous comparative studies from direct observations (Jaeggi et al., 290 2020), trapping data (Valomy et al., 2015) and from sleeping sites (Agnani et al., 2018). Table

1 states the information which every study on wild living animals should report in their methods and results section, to make information about the social organization of the study population available for comparative studies, even when the study focus is on something else. While Table 1 lists this information in the order of missing information, in any publication it 295 should typically be reported as: (1) proportion of individuals within the study area trapped, marked, radio-tracked, and observed, (2) frequency of trapping / observation event, (3) sex

297 of individuals studied, (4) composition of social units, (5) in studies using radio-tracking the 
home range overlap with all individuals should be stated, and (6) which individuals shared nesting / sleeping / resting sites and how regularly. It is very important that all of this 300 information is also reported for species which are believed to live solitarily, because as demonstrated here for Xenarthra, important deviation from this main form of social organization might occur. Furthermore, it has been empirically demonstrated that many species that were believed to be solitary living in fact live in pairs or groups (Agnani et al., 2018; Valomy et al., 2015).

Similar considerations as for reporting data on social organization may also apply to the three other components of the social system. For the mating system, it is now common that the number of extra-pair paternities are reported, how many offspring each male sired in a group, and the frequency of multiple paternities, which can then be used in comparative studies (Dobson et al., 2018). For the social structure, different measures of the social networks must be reported in a way that they can be used for comparative studies (see https://github.com/bansallab/asnr). For the parental care system, it is important to report not only whether maternal, paternal and allo-parental care by breeders and non-breeders

occurs, but also how commonly parental behaviour is shown by the different group members, and how many social units show which category of parental care system (Griesser et al., 2017;

Griesser \& Suzuki, 2016). Therefore, our demand to accurately report data on social organization can be extended to the other components of the social system.

\section{CONCLUSIONS}

During the process of building a database on mammalian social organization we came 320 across several peer-reviewed publications that indicated that they had collected data we 
321 could use for the database, but this information was not presented in a way that we could

322 reliably determine the composition of social units. Here we argue for field researchers to 323 always report life history data, making it possible to accurately determine the social 324 organization; especially to report the proportion of population studied, frequency of trapping 325 / observation events, sex of individuals studied, the composition of social units and sharing of 326 home ranges and sleeping sites. These recommendations are not only important for 327 mammals, but also for databases in other taxa, such as fish (Tanaka et al., 2018) and birds 328 (Griesser \& Suzuki, 2016).

\section{Acknowledgements}

331 We are grateful for the help of several interns in extracting data on social organization. 332 Comments by W. Goymann, M. Griesser and one anonymous referee significantly improved 333 the manuscript. We are also grateful to E. Kudze and T. Godding for helping to edit the grammar and language. This study was supported by the CNRS and the University of 335 Strasbourg.

\section{References}

Agnani, P., Kauffmann, C., Hayes, L. D., \& Schradin, C. (2018). Intra-specific variation in social organization of Strepsirrhines. American Journal of Primatology, 80(5), e22758. doi:doi:10.1002/ajp.22758 
341 Callaghan, C. T., Nakagawa, S., \& Cornwell, W. K. (2021). Global abundance estimates for

342

9,700 bird species. Proceedings of the National Academy of Sciences, 118(21), e2023170118. doi:10.1073/pnas.2023170118

Chak, S. T. C., Duffy, J. E., Hultgren, K. M., \& Rubenstein, D. R. (2017). Evolutionary transitions towards eusociality in snapping shrimps. Nature Ecology \& Evolution, 1(4), 1-7.

Clutton-Brock, T., \& Janson, C. (2012). Primate socioecology at the crossroads: Past, present, and future. Evolutionary Anthropology: Issues, News, and Reviews, 21(4), 136-150. doi:https://doi.org/10.1002/evan.21316

Clutton-Brock, T., \& Sheldon, B. C. (2010). Individuals and populations: the role of long-term, individual-based studies of animals in ecology and evolutionary biology. Trends in Ecology \& Evolution, 25(10), 562-573.

Cockburn, A. (2006). Prevalence of different modes of parental care in birds. Proceedings of the Royal Society B: Biological Sciences, 273(1592), 1375-1383.

Cornwallis, C. K., Botero, C. A., Rubenstein, D. R., Downing, P. A., West, S. A., \& Griffin, A. S. (2017). Cooperation facilitates the colonization of harsh environments. Nature Ecology \& Evolution, 1(3), 1-10.

Desbiez, A., Kluyber, D., Massocato, G., Oliveira-Santos, L., \& Attias, N. (2019). Spatial ecology of the giant armadillo Priodontes maximus in Midwestern Brazil. Journal of Mammalogy, 101(1), 151-163.

Desbiez, A. L. J., Massocato, G. F., Kluyber, D., \& Santos, R. C. F. (2018). Unraveling the cryptic life of the southern naked-tailed armadillo, Cabassous unicinctus squamicaudis (Lund, 1845), in a Neotropical wetland: home range, activity pattern, burrow use and reproductive behaviour. Mammalian Biology, 91(1), 95-103. 
Di Blanco, Y. E., Jiménez Pérez, I., \& Di Bitetti, M. S. (2017). Habitat selection in reintroduced giant anteaters: the critical role of conservation areas. Journal of Mammalogy, 96(5), 1024-1035.

Dobson, F. S., Abebe, A., Correia, H. E., Kasumo, C., \& Zinner, B. (2018). Multiple paternity and number of offspring in mammals. Proceedings of the Royal Society B, 285(1891), 20182042.

Falconi, N., Vieira, E. M., Baumgarten, J., Faria, D., \& Giné, G. A. F. (2015). The home range and multi-scale habitat selection of the threatened maned three-toed sloth (Bradypus torquatus). Mammalian Biology, 80(5), 431-439.

Firman, R. C., Rubenstein, D. R., Moran, J. M., Rowe, K. C., \& Buzatto, B. A. (2020). Extreme and variable climatic conditions drive the evolution of sociality in Australian rodents. Current Biology, 30(4), 691-697. e693.

Garamszegi, L. Z. (2014). Modern phylogenetic comparative methods and their application in evolutionary biology. Berlin: Springer.

Garcés-Restrepo, M. F., Peery, M. Z., Reid, B., \& Pauli, J. N. (2017). Individual reproductive strategies shape the mating system of tree sloths. Journal of Mammalogy, 98(5), 14171425.

Gonzalez, J.-C. T., Sheldon, B. C., \& Tobias, J. A. (2013). Environmental stability and the evolution of cooperative breeding in hornbills. Proceedings of the Royal Society B: Biological Sciences, 280(1768), 20131297.

Griesser, M., Drobniak, S. M., Nakagawa, S., \& Botero, C. A. (2017). Family living sets the stage for cooperative breeding and ecological resilience in birds. PLoS biology, 15(6), e2000483. 
Griesser, M., \& Suzuki, T. N. (2016). Occasional cooperative breeding in birds and the robustness of comparative analyses concerning the evolution of cooperative breeding. Zoological Letters, 2, 7. doi:10.1186/s40851-016-0041-8

Huck, M., Di Fiore, A., \& Fernandez-Duque, E. (2020). Of apples and oranges? The evolution of "monogamy" in non-human primates. Frontiers in Ecology and Evolution, 7(472). doi:10.3389/fevo.2019.00472

Jaeggi, A. V., Miles, M. I., Festa-Bianchet, M., Schradin, C., \& Hayes, L. D. (2020). Variable social organization is ubiquitous in Artiodactyla and probably evolved from pair-living ancestors. Proceedings of the Royal Society B: Biological Sciences, 287(1926), 20200035. doi:doi:10.1098/rspb.2020.0035

Jetz, W., \& Rubenstein, D. R. (2011). Environmental uncertainty and the global biogeography of cooperative breeding in birds. Current Biology, 21(1), 72-78.

Kappeler, P. M. (2019). A framework for studying social complexity. Behavioral Ecology and Sociobiology, 73(1), 13. doi:10.1007/s00265-018-2601-8

Kappeler, P. M., \& van Schaik, C. P. (2002). Evolution of primate social systems. International Journal of Primatology, 23(4), 707-740.

Lott, D. F. (1984). Intraspecific variation in the social systems of wild vertebrates. Behaviour, $88,266-325$.

Lukas, D., \& Clutton-Brock, T. (2017). Comparative studies need to rely both on sound natural history data and on excellent statistical analysis. Royal Society open science, 4(11), 171211.

Lukas, D., \& Clutton-Brock, T. H. (2013). The evolution of social monogamy in mammals. Science, 341(6145), 526-530. doi:10.1126/science.1238677 
McDonough, C. M. (2000). Social organization of nine-banded armadillos (Dasypus novemcinctus) in a riparian habitat. The American Midland Naturalist, 144(1), 139-151.

Medri, Í. M., \& Mourão, G. (2005). Home range of giant anteaters (Myrmecophaga tridactyla) in the Pantanal wetland, Brazil. Journal of Zoology, 266(4), 365-375.

Nowak, R. M., \& Wilson, E. (1999). Walker`s Mammals of the World (6th ed.). Baltimore: John Hopkins University Press.

Pauli, J. N., \& Perry, M. Z. (2012). Unexpected strong polygyny in the brown-throated threetoed sloth. PLoS ONE, 7(12), e51389. doi:10.1371/journal.pone.0051389

Ramachandran, R., Bugbee, K., \& Murphy, K. (2021). From open data to open science. Earth and Space Science, 8. doi:10.1029/2020EA001562

Reichman, O., Jones, M., \& Schildhauer, M. (2011). Challenges and opportunities of open data in ecology. Science (New York, N.Y.), 331, 703-705. doi:10.1126/science.1197962

Rodrigues, F. H., Marinho-Filho, J., \& Dos Santos, H. G. (2001). Home ranges of translocated lesser anteaters Tamandua tetradactyla in the cerrado of Brazil. Oryx, 35(2), 166-169.

Schradin, C. (2017). Comparative studies need to rely both on sound natural history data and on excellent statistical analysis. Royal Society open science, 4(9), 170346.

Schradin, C., \& Hayes, L. D. (2017). A synopsis of long-term field studies of mammals: achievements, future directions, and some advice. Journal of Mammalogy, 98(3), 670677. doi:10.1093/jmammal/gyx031

Schradin, C., Hayes, L. D., Pillay, N., \& Bertelsmeier, C. (2018). The evolution of intraspecific variation in social organization. Ethology, 124, 527-536. doi:doi:10.1111/eth.12752

Shaw, J. H., Machado-Neto, J., \& Carter, T. S. (1987). Behavior of free-living giant anteaters (Myrmecophaga tridactyla). Biotropica, 255-259. 
Tanaka, H., Frommen, J. G., Koblmüller, S., Sefc, K. M., McGee, M., Kohda, M., . . Taborsky, M. (2018). Evolutionary transitions to cooperative societies in fishes revisited. Ethology, 124(11), 777-789.

Taube, E., Vié, J. C., Fournier, P., Genty, C., \& Duplantier, J. M. (1999). Distribution of Two Sympatric Species of Sloths (Choloepus didactylus and Bradypus tridactylus) along the Sinnamary River, French Guiana 1. Biotropica, 31(4), 686-691.

Valomy, M., Hayes, L. D., \& Schradin, C. (2015). Social organization in Eulipotyphla: evidence for a social shrew. Biology Letters, 11(11), doi:10.1098/rsbl.2015.0825.

Vaughan, C., Ramírez, O., Herrera, G., \& Guries, R. (2007). Spatial ecology and conservation of two sloth species in a cacao landscape in Limón, Costa Rica. Biodiversity and Conservation, 16(8), 2293-2310.

Wildman, D. E., Uddin, M., Opazo, J. C., Liu, G., Lefort, V., Guindon, S., . . Goodman, M. (2007). Genomics, biogeography, and the diversification of placental mammals. Proceedings of the National Academy of Sciences, 104(36), 14395-14400.

Wilson, D. E., \& Mittermeier, R. A. (2015). Handbook of the Mammals of the World Volume 5: Monotremes and Marsupials. Lynx Edicions, Barcelona.

Wilson, D. E., \& Mittermeier, R. A. (2018). Handbook of the Mammals of the World Volume 8: Insectivores, Sloths and Colugos. Lynx Edicions, Barcelona. 
Table 1 Reasons why field studies could not be used to determine the social organization of

455 the study population. For Xenarthra, data from a detailed literature survey trying to identify

456 all published field studies are reported. Additional examples from other mammalian taxa are

457 also reported.

\begin{tabular}{|c|c|c|}
\hline $\begin{array}{l}\text { Missing information to determine social } \\
\text { organization }\end{array}$ & $\begin{array}{l}\text { Total number of } \\
\text { field studies on } \\
\text { Xenarthra (ESM1) }\end{array}$ & $\begin{array}{c}\text { Examples from } \\
\text { other mammalian } \\
\text { taxa (ESM2) }\end{array}$ \\
\hline Composition of social units not stated. & 29 & $\begin{array}{c}\text { Carnivora: } 1 \\
\text { Chiroptera: } 2 \\
\text { Marsupialia: } 1 \\
\text { Monotremes: } 3\end{array}$ \\
\hline Sex of individuals not stated. & 23 & $\begin{array}{c}\text { Perissodactyla: } 6 \\
\text { Carnivora: } 2 \\
\text { Chiroptera: } 2 \\
\text { Rodents: } 2 \\
\text { Marsupialia: } 4 \\
\text { Monotremes: } 1\end{array}$ \\
\hline Occupancy of sleeping sites. & 6 & Monotremes: 1 \\
\hline Home range overlap not stated. & 3 & Monotremes: 1 \\
\hline Frequency of trapping events not stated. & 2 & Monotremes: 1 \\
\hline $\begin{array}{l}\text { Not stated what proportion of the population } \\
\text { was studied. }\end{array}$ & 1 & \\
\hline
\end{tabular}

